\title{
A Quantitative Analysis of Swedish Fertility Dynamics: 1751-1990
}

\author{
Zvi Eckstein \\ Tel Aviv University and Boston University \\ Pedro Mira \\ CEMFI (Spain) \\ Kenneth I. Wolpin \\ University of Pennsylvania
}

Working Paper No. 9713

September 1997

E-mail addresses: eckstein@econ.tau.ac.il,mira@cemfi.es, wolpink@ssc.upenn.edu. CEMFI, Casado del Alisal 5, 28014 Madrid, Spain.

Tel: 341 4290551, fax: 341 4291056, http://www.cemfi.es. 


\begin{abstract}
This paper analyzes the relationship between age-specific fertility, mortality and real wages in Sweden during the demographic transition. We take an overlapping generations model of life cycle fertility and fit it to actual Swedish time-series data over the past two and a half centuries. The model fits the data well, accurately portraying the total fertility decline from more than four children per female before the mid-19'th century to about two children today. About $80 \%$ of this decline was in fertility that occurred at female ages over 30 . The fitted model implies that reductions in child mortality over this period is the most important factor explaining the fertility decline, while increases in the real wage can explain only less than one-third of the decline in fertility. However, their combined effect was considerably larger than a simple summing up would predict. The fertility decline was magnified as well by the combination of increasing real wages and rising adult survival rates. In addition, we find that a model that is estimated based only on pre-transition data would actually overstate the subsequent fertility decline.
\end{abstract}




\section{Introduction}

This paper analyzes the relationship between fertility, mortality and real wages in Sweden during the period from the mid-18th century to the present within the context of an overlapping generations model of life cycle fertility. We have two basic goals. The first is to determine whether fertility behavior that is induced by movements in real wages and age-specific mortality rates operating through a formal economic model can fit the cohort-specific life cycle pattern of births observed in Sweden over the past 200 years. The second goal, contingent on an affirmative answer to the first, is to provide an assessment of the importance of changes in mortality and real wages as explanations of the demographic transition.

The demographic transition in Sweden appears to have begun with the 1856 birth cohort (see Figure 1). Completed fertility of the 1736 to 1851 (female) birth cohorts fluctuated between 4.1 and 4.6. It first fell to under four with the 1861 cohort, to under three with the 1886 cohort and to under two with the 1901 cohort. The decline in fertility was concentrated in the latter part of the life cycle. Between the 1851 and 1901 cohorts, the number of children born at maternal ages between 15 and 29 dropped from 1.6 to 1.1, which accounts for just 20 percent of the fall in completed fertility. On the other hand, the concomitant fall in fertility at maternal ages between 30 and 44 was from 2.6 to 0.8 .

Child survival rates to age 15 began to increase well before the decline in fertility (see Figure 2). The 1736 female birth cohort could look forward to a survival rate among their children of 59 percent. The child survival rate increased gradually thereafter. A plateau was reached with the 1806 cohort at 68 percent, followed by a sustained and rapid rise in survival rates beginning with the 1841 cohort. Adult survival rates, survival to age 60 conditional on reaching age 15, were relatively stable for the birth cohorts between 1736 and 1786 at about 50 percent. A steady increase began with the 1791 cohort, first passing 60 percent with the 1816 cohort, 70 percent with the 1871 cohort, and 
85 percent with the 1916 cohort. Sustained growth in real wages began with the 1826 birth cohort, slightly prior to the start of the demographic transition (see Figure 3).

Demographic transition theory posits that a necessary precondition for fertility decline is a reduction in infant and child mortality (see the discussion in Preston (1978)). A simple target fertility model is consistent with this proposition: to have $\mathrm{x}$ surviving children (the target), $\mathrm{x} / \mathrm{s}$ children must be borne when the survival rate is s. Moreover, as in Sweden, a substantial decline in mortality did indeed precede fertility decline in almost every developed country. However, in a recent summary of the voluminous theoretical and empirical literature in demography and economics that has attempted to understand better the causes of the demographic transition, Cohen and Montgomery (in press), in referring to demographic transition theory, conclude that " a mountain of evidence refutes such a simple description of real-world events."

Empirical approaches to the analysis of aggregate fertility data (time-series and cross- section) have been related only loosely to economic theory. ${ }^{1}$ On the other hand, the theoretical literature on growth and the demographic transition has been related to the data only in a qualitative way. ${ }^{2}$ Unlike that literature, the approach adopted in this paper is to fit an explicit optimization model of life cycle fertility to the data.

The overlapping generations model we adopt assumes that agents live for a maximum of five 15-year long periods, making fertility decisions in the second and third (ages 15 to 29 and 30 to 44). Utility at each age is derived from consumption and the existing stock of children. Each agent is endowed with a unit of labor and cannot transfer resources across periods. We assume that

\footnotetext{
${ }^{1}$ See for example the VAR approach of Eckstein, Schultz and Wolpin (1982) and the simultaneous equations approach of Schultz (1988).

${ }^{2}$ Overlapping generations models that jointly address the issues of economic growth and the demographic transition include Razin and Ben Zion (1976), Eckstein, Stern and Wolpin (1988), Lee (1988), Becker and Barro (1988), Becker, Murphy and Tamura (1990), Ehrlich and Lui (1991) and Gal-Or and Weill (1996).
} 
a given stock of existing children is a "basic need" (estimated as a parameter in our model), at the very least in order to maintain the species. Children are costly to bear and to rear. We model the latter as a time cost which subtracts from labor market time and, thus, which is increasing in the real wage. Agents have perfect foresight about future age-specific survival rates and future wages, which are taken to be exogenous.

The model contains seven parameters. We fit the model to 43 five-year birth cohorts, born between 1736 and 1946, by minimizing the sum of squared differences between actual and predicted fertility in each of the two fertile life cycle stages. The model fits the data well, accurately portraying the pattern of Swedish fertility decline. Given this outcome, we are able to use the fitted model to quantify the importance of alternative explanations of the demographic transition in Sweden. Our results imply that wage increases and reductions in infant and child mortality both contributed to the fertility decline during the transition period. The reduction in infant and child mortality over this period is the most important factor explaining the fertility decline, while increases in the real wage can explain only less than one-third of the decline in fertility. The combined impact of the decline in infant and child mortality and the increase in real wages is larger than the sum of each change. These factors together with the increase in adult survival fully predict the decline in fertiltiy that is observed in the data.

In addition, we investigated the question of whether a model that is estimated using data on birth cohorts only up to 1856 would accurately forecast the transition. That is, we considered the possibility that social scientists at the end of the 19th century might have predicted the demographic transition if they had available current methodology. The result from this exercise is that even though we use pre-transition data, the estimates actually overstate the fertility decline that occurred thereafter. We compared the mean square error of these forecasts to those obtained from time-series regression specifications that explicitly minimized the forecast mean square error. The model did not perform worse. 
The rest of the paper is organized as follows. The next section presents the life cycle fertility model. In Section 3, we describe the Swedish data in detail. Parameter estimates are provided in Section 4 and explanations of the transition derived from these results are given in Section 5. In Section 6 we examine the out-of-sample forecasts of the model based on pre- transition data estimates of the model. Section 7 summarizes and concludes.

\section{A Life Cycle Model of Fertility}

We adopt a perfect foresight overlapping generations model in which each agent may live for as many as five (fifteen year) periods. In the first period, the agent is a child and makes no decisions. In the second and third periods, the agent decides on her fertility, i.e., the number of children to have in each period. The agent is endowed with a unit of labor and works in each adult period at a fixed wage. Children provide psychic benefits, but are costly both in time and in consumption goods. There is a level of surviving children that the couple takes as a "basic need", that is, where the marginal utility of an additional child is infinite. Children and adults die according to a known survival schedule.

More formally, the representative agent of cohort t maximizes the lifetime utility function

$$
\sum_{a=1}^{4} \beta_{a t}\left[\ln c_{a t}+\alpha_{1} \ln \left(N_{a t}-\underline{N}_{a}\right)+\alpha_{2 a} \ln c_{a t} \ln N_{a t}\right]
$$

where $\beta_{a t}$ is the effective discount factor, $\beta_{a t}=\delta^{a-1} s_{a t}, \delta$ is the subjective discount factor, $s_{a t}$ is the survival rate to age $a, a=1, . ., 4$, for the cohort born at calendar time t, $c_{a t}$ is consumption of cohort t at age a, $N_{a t}$ is the stock of surviving children at age a of cohort t and $\underline{N}_{a}$ is the basic need level on the stock of children at age a. Age $a=0$ corresponds to childhood. $\alpha_{1}$ measures the importance of children relative to consumption and $\alpha_{2 a} \neq 0$ implies that preferences can deviate from a (unit) constant elasticity of substitution form. 
Given the perfect foresight assumption, the number of children that will survive to any age is known, and is given by,

$$
\begin{aligned}
& N_{1 t}=n_{1 t} s_{1 t+1} \\
& N_{2 t}=n_{1 t} s_{2 t+1}+n_{2 t} s_{1 t+2} \\
& N_{3 t}=n_{1 t} s_{3 t+1}+n_{2 t} s_{2 t+2} \\
& N_{4 t}=n_{1 t} s_{4 t+1}+n_{2 t} s_{3 t+2},
\end{aligned}
$$

where $N_{a t}$ is equal to the number of children born at age $a$ to cohort $t$. Notice that utility is derived from children during the period only if they survive the period, i.e., to the next age. This assumption is made to accommodate the fact that mortality during the first fifteen years of life is concentrated within the first few years of life. ${ }^{3}$

Consumption at age a for cohort $t$ is given by

$$
c_{a t}=w_{a t} \ell_{a t}-b_{a} n_{a t},
$$

where $w_{a t}$ and $\ell_{a t}$ are the wage and work time at age a for cohort t. The goods cost of bearing a child, $b_{a}$, is allowed to vary by the life cycle stage of the parent generation. Resources cannot be transferred between periods. Work time, $\ell_{a t}$ is given by

$$
\ell_{a t}=1-m n_{a t} s_{1 t+a}, a=1,2,
$$

where $m$ is the time cost associated with rearing a surviving child. Notice that the time cost is incurred only if the child survives to adulthood, while the goods cost is a fixed cost independent of survival.

To close the model, we assume that labor of different ages is homogeneous and technology is linear in aggregate work time. The wage, in this case, is

\footnotetext{
${ }^{3}$ Mortality in the first year of life accounted for approxmately 70 percent of total child mortality (ages 0-15) well into latter half of the 19'th century. Subsequent proportions were in the 80 to 90 percent range.
} 
exactly equal to per-capita income and is technologically given. Wage change is, thus, due only to exogenous technology change. Survival rates are likewise assumed to be technologically determined outside the model. ${ }^{4}$

The first order conditions for first and second period births $\left(n_{1 t}, n_{2 t}\right)$, allowing for corner solutions, are:

$$
\sum_{a=i}^{4} \beta_{a t}\left[\frac{\alpha_{1}}{N_{a t}-\underline{N}_{a}}+\frac{\alpha_{2 a} \ln c_{a t}}{N_{a t}}\right] s_{a-i+1, t+i} \leq \lambda_{i t}\left(w_{i t} m s_{1, t+i}+b_{i}\right)
$$

for $i=1,2$, where $\lambda_{i t}=\beta_{i t}\left(1-\alpha_{2 i} \ln N_{i t}\right) / c_{i t}$ is the marginal utility of income in period $i$.

\section{Data}

Sweden is one of only a few countries for which there is sufficient historical data to assess the ability of economic models to explain long-term movements in fertility that span a country's demographic transition period. The Historical Statistics of Sweden (1969) provide age-specific fertility rates (live births per thousand women) by five year age intervals and by five year periods beginning in 1751 . The same source also provides information on agespecific death (hazard) rates reported in five year age groups by ten year intervals over the same historical period. Nominal wages and commodity prices are also available annually since 1750 from several data sources: the $\underline{\text { Statistical Yearbooks of Sweden, the ILO Yearbook of Labour Statistics, }}$

A History of Prices in Sweden by L. Jorberg, and European Historical Statisitics by B.R. Mitchell.

The data on fertility, mortality and real wages are constructed to be consistent with the cohort structure of the model. We provide the details of that

\footnotetext{
${ }^{4}$ For a comprehensive paper on the relationship between consumption and survival for this historical period see Fogel(1994).
} 
construction as well as the main characteristics of the demographic transition in Sweden.

\section{Fertility}

Following the model, only two life cycle fertility periods are considered, fertility between the ages of 15 and $29, n_{1 t}$, for female birth cohort $t$, and fertility between the ages of 30 and $44, n_{2 t}$. From the data on age-specific fertility rates, we constructed the cohort-specific fertility rates, $n_{1 t}$ and $n_{2 t}$, for female birth cohorts separated by 5 years (on average). Thus, for example, to obtain first-period fertility for the females born between 1731 and 1740, which we denote as the 1736 birth cohort, we add the average (five-year) fertility rates of the 15 to 19 year olds in 1751-1755, the 20 to 24 year olds in 1756-1760, and the 25 to 29 year olds in 1761-1765. We do the analogous calculation to obtain first-period fertility for the 1741 cohort (born between 1736 and 1745), the 1746 cohort, etc. Second-period fertility adds the average (five year) fertility rates for the 30 to 34,35 to 39 , and 40 to 44 age groups over the appropriate years for each cohort. The 1946 birth cohort is the last one for which we are able to construct a complete lifetime fertility profile. There are 43 different cohorts in five-year intervals over the period of the data. ${ }^{5}$

Figure 1 depicts fertility paths starting with the 1736 birth cohort and ending with the 1946 cohort. Cumulative or completed cohort fertility $\left(n_{t}=\right.$

\footnotetext{
${ }^{5}$ Given this construction of the two life cycle fertility periods, only cohorts separated by 30 years are completely independent, that is, having no overlap in individuals or in years. For example, the 1736 and 1741 cohorts have in common females who were born between 1736 and 1741, while the 1736 and 1746 cohorts each have a component of their first period fertility determined during the 1761-1765 period, in the former case for the 25 to 29 year olds and in the latter case for the 15 to 19 year olds. In this sense, age-specific fertility observations are independent (in individuals and in years) only for cohorts separated by at least 15 years. However, their fertility rates at different periods overlap in years so that the number of completely independent life-cycle fertility observations is only 8. Likewise, the number of birth cohorts independent in individuals is at most 22 (at 10 years intervals), and the number of independent age-specific fertility observations is at most 15 , for cohorts separated 15 years.
} 
$\left.n_{1 t}+n_{2 t}\right)$ was greater than four for the first 25 cohorts, reaching a peak of 4.59 for the 1801 cohort and going down to 4.07 for the 1856 cohort. Although the 1856 cohort had the lowest completed fertility of these 25 cohorts, the 1751 cohort had only .04 more children. Thus, in the context of cohorts up to the mid-19th century, the level of the 1856 cohort's fertility and the fall in fertility between the 1851 and 1856 cohorts, while unusual, might not have appeared exceptional; in fact, the fall between the 1736 and 1741 cohorts was as large. Between the 1856 and 1871 cohorts, completed fertility fell by .44 children. Although this drop was not unprecedented, total cohort fertility fell below four children for the first time. It would not have been unreasonable with that information alone to have supposed that a new trend was emerging.

Subsequent changes were larger. Between the 1871 and 1886 cohorts completed fertility fell by .77 children and between the 1886 and 1901 cohorts by .97 children. The 1901 cohort did not even attain the replacement level of fertility, even before accounting for infant and child mortality. Subsequently, completed fertility recovered slightly and remained roughly constant at around 2 children for the 20th century cohorts. Although fertility fell from 4.07 to 3.63 children between the 1856 and 1871 cohorts, because of rising survival rates the number of children surviving to adulthood (age 15) fell only from 2.93 to 2.83. Surviving children fell to 2.37 with the 1886 cohort, and even that was higher than the same Figure for the 1751 cohort. Thus, it wasn't until the 1886 cohort that the number of surviving children began to decline significantly.

The number of children born to women between the ages of 15 and 29, the first life cycle period $n_{1 t}$, declined at a slow but fairly steady rate through the 1886 cohort, from 1.9 children for the 1736 cohort to 1.5 children for the 1886 cohort. It declined sharply thereafter, falling to as low as 0.97 children for the 1906 and 1911 cohorts. However, fertility in this age group rose again to 1.18 children for the 1916 cohort and reached pre-1900 levels (1.5-1.6) for cohorts between 1931 and 1946 .

Given this pattern, it is clear that the decline in completed fertility described above that occurred after the 1856 cohort must have been due pre- 
dominantly to a decline in fertility at older ages. As Figure 1 shows, prior to mid-19th century cohorts, the number of children born to women between 30 and 44 years old, in the second life cycle period, $n_{2 t}$, had a flat or slightly rising trend. However, between the 1856 and 1871 cohorts, $n_{2 t}$ declined from 2.48 to 2.06 children. The fall was considerably greater between the 1871 and 1886 cohorts, by .71 children, with fertility in that age group reaching 1.35 children for the 1886 cohort. And, by the 1901 cohort, $n_{2 t}$ (children born between 1931 to 1944) was only .79 children. The decline in second-period fertility continued after the 1916 cohort, with .63 and .49 children born to the 1931 and 1946 cohorts. Strikingly, the 1946 cohort's fertility up to age 30 looked almost the same as the fertility of mid-19th century cohorts; the reduction in completed fertility of about 2.5 children that occurred in that interval was due almost entirely to a drop in fertility beyond the age of 30 .

\section{Survival}

Corresponding age-specific survival rates were constructed assuming that the average survival rate over each ten year period was the same for each of its two five year subgroups. Given that assumption, survival rates were calculated for each five year age group and for each cohort. From that construction, we calculated corresponding age- and cohort-specific survival rates by 15 year age intervals for each of the cohorts from 1736 to 1916, i.e., for age intervals 0-14, 15-29, 30- 44, 45-59, 60+.

Figure 2 depicts the cohort trend with respect to those two features of survival schedules that would be most relevant to the fertility decision, the infant and child survival rate relevant to the children born to the specific cohorts (the average survival rate of children born to women aged 15 to 44), and the survival rate of the cohort to age 60 conditional on survival to adulthood (age 16). The infant and child survival rate, viewed from the perspective of the childbearing generation, rose almost continuously from the 1751 cohort on, paused briefly for the early 19th century cohorts, and then rose at a somewhat 
faster pace starting with the 1841 cohort. Around 40 percent of children born in the middle and late 1700's did not survive past age 15. By the late 1800's around 25 percent did not survive to adulthood, while by the the time of the 1901 cohort about 15 percent did not survive childhood. The survival of children continued to rise: today, survival to age 15 is .99 .

Figure 2 also shows that although the infant and child survival rate relevant to women at their childbearing ages began to rise with the mid-1700's cohorts, the survival rate of the childbearing generation to age 60 , conditional on reaching adulthood, did not begin to rise until the 1796 cohort. The 1781 cohort had a conditional old-age survival rate of .40 and that figure doubled by the 1901 cohort. Conditional on survival to age 15, the probability of survival to age 60 had reached 90 percent in 1990 .

An often-noted fact is that the decline in fertility was delayed relative to the infant and child mortality decline, leading to a period of rapid population growth. ${ }^{6}$ If the decline in fertility was, at least in part, the result of declining mortality, as has been argued, then why was the decline in fertility so delayed? And why did completed fertility stay at around two children starting with the early 20'th century cohorts, while child survival continued to increase by more than ten percent?

Wages

For the period 1750-1914 the real wage series is the day rate for male agricultural workers deflated by the price of rye (Jorberg data), for 19151959 it is the summer day wage of male casual labor deflated by a cost of living index (Mitchell data), and for 1960 on it is the hourly manufacturing wage deflated by a cost of living index (Statistical Yearbook and the Yearbook of Labour Statistics). Annual real wage data are averaged over 15 year periods to obtain age- and cohort-specific real wages. There do not exist historical age-specific wage data, so that all life cycle real wage variation is due to calendar-time variation.

\footnotetext{
${ }^{6}$ See, for example, Coale (1987) and Matthieson and McCann (1976) .
} 
Figure 3 depicts the natural logarithm of real wages pertaining to the cohorts in their first two adult age periods (corresponding to the periods associated with $n_{1 t}$ and $\left.n_{2 t}\right), \ln w_{1 t}$ and $l n w_{2 t}$, for the 1736 through 1945 cohorts. Because there is no life cycle variation in the data, $\ln w_{1 t}$ is equal to $\ln w_{2 t-1}$. Real wages during the first two adult periods of the cohorts up to 1826 were stagnant. Between the 1826 and 1901 cohorts, real wages approximately tripled, and between the 1901 and 1946 cohorts they tripled again.

As with mortality, the timing of the fertility transition did not coincide with the rise in real wages. The growth in real wages preceded the fall in fertility by 30 years. The negative relationship between fertility and real wages that occurred during the transition was reversed for the cohorts whose prime childbearing years coincided with the great depression, the 1906 and 1911 cohorts, when real wages and fertility both fell.

\section{Model Parameter Estimates}

In this section, we present parameter estimates based on the fertility, mortality and real wage observations of all birth cohorts between 1736 and 1946. There are in total 86 observations, 43 for each of the two fertility periods. ${ }^{7}$ The model is fit by minimizing the sum of the squared deviations between the model's predictions and the actual values of the two age-specific fertility rates. This involves solving each cohort's optimization problem for a given set of parameters, i.e., solving for $n_{1 t}$ and $n_{2 t}$, and finding the parameters that lead to smallest squared prediction errors. The optimization problem does not have a closed form solution, and requires the use of a numerical non-linear

\footnotetext{
${ }^{7}$ In order to use observations on age-specific fertility rates for all cohorts between 1921 and 1946, it was necessary to forecast real wages and survival rates between 1991 and 2020. Real wages were obtained extrapolating the average growth rate between 1975 and 1990. Survival rates were constructed assuming constant age-specific mortality rates at their 1990 levels.
} 
Table 1: Parameter "Estimates"

\begin{tabular}{|ccccccc|}
\hline$\alpha_{1}$ & $\alpha_{21}$ & $\alpha_{22}$ & $b$ & $m$ & $\underline{N}_{1}$ & $\underline{N}_{2}$ \\
.2886 & 0.0147 & -.6668 & .1128 & .2886 & .57 & 1.4348 \\
\hline
\end{tabular}

constrained optimization algorithm..$^{8}$

The parameters that result from fitting the model to the full sample are shown in Table 1. The actual and the model's predicted values for first period, second period and completed fertility per woman are presented in Table $2 .^{9}$

The estimates of the utility function parameters indicate that utility is increasing in children $\left(\alpha_{1}>0\right)$ and that consumption is a complement in utility with the stock of first-period surviving children $\left(\alpha_{21}>0\right)$, but a substitute with the stock of second-period surviving children $\left(\alpha_{22}<0\right) .{ }^{10}$ This result seems to be driven by the sharp decline in second-period fertility that occurred during the demographic transition, while at the same time real wages were rising and first-period fertility stayed roughly constant. Because utility in the model is derived from the stock of children, parents would prefer to have children when they are young so as to enjoy them over a longer period of time. One reason why they do not have all their children when they are young is because they are constrained in the model from borrowing against future income. As income

\footnotetext{
${ }^{8}$ We use GAUSS 3.2 and the Constraint Optimization library to solve a cohort's lifecycle optimization problem. Initially we minimize the sum of squared deviations between the actual and the model's predicted fertility by using a grid on all the seven parameters in the relevant parameter space. We then switch to a downhill simplex algorithm to close in on the best fit.

${ }^{9}$ Recall that observations for all 43 cohorts are not fully independent (see discussion in section 3 ). The model was also fit to the samples obtained when we only use cohorts separated by 15 years and by 30 years, giving sample sizes of 15 and 8 cohorts, respectively. Parameter estimates in both cases are slightly different, but the results are qualitatively the same.

${ }^{10}$ That is, the marginal utility of children in the second (first) period decreases (increases) with the level of consumption. Note that we restrict $\alpha_{22}=\alpha_{23}=\alpha_{24}$.
} 
Table 2: Actual and Predicted Fertility

\begin{tabular}{|c|cc|cc|cc|}
\hline & \multicolumn{3}{|c|}{$n_{1 t}$} & \multicolumn{2}{|c|}{$n_{2 t}$} & \multicolumn{3}{c|}{$n_{t}$} \\
Cohort & Actual & Predicted & Actual & Predicted & Actual & Predicted \\
1736 & 1.90 & 1.84 & 2.64 & 2.93 & 4.54 & 4.77 \\
1741 & 1.86 & 1.85 & 2.51 & 2.87 & 4.37 & 4.72 \\
1746 & 1.71 & 1.86 & 2.53 & 2.83 & 4.24 & 4.69 \\
1751 & 1.74 & 1.95 & 2.37 & 2.67 & 4.11 & 4.62 \\
1756 & 1.70 & 1.93 & 2.42 & 2.60 & 4.12 & 4.53 \\
1761 & 1.68 & 1.90 & 2.54 & 2.49 & 4.22 & 4.40 \\
1766 & 1.77 & 1.83 & 2.50 & 2.42 & 4.27 & 4.25 \\
1771 & 1.80 & 1.79 & 2.42 & 2.37 & 4.22 & 4.17 \\
1776 & 1.74 & 1.69 & 2.49 & 2.45 & 4.22 & 4.13 \\
1781 & 1.69 & 1.60 & 2.63 & 2.62 & 4.32 & 4.22 \\
1786 & 1.70 & 1.55 & 2.69 & 2.71 & 4.39 & 4.26 \\
1791 & 1.73 & 1.59 & 2.79 & 2.67 & 4.52 & 4.26 \\
1796 & 1.85 & 1.67 & 2.72 & 2.63 & 4.57 & 4.31 \\
1801 & 1.86 & 1.72 & 2.73 & 2.57 & 4.59 & 4.29 \\
1806 & 1.85 & 1.67 & 2.72 & 2.55 & 4.57 & 4.22 \\
1811 & 1.77 & 1.65 & 2.75 & 2.48 & 4.52 & 4.13 \\
1816 & 1.67 & 1.60 & 2.74 & 2.55 & 4.41 & 4.16 \\
1821 & 1.55 & 1.58 & 2.84 & 2.65 & 4.39 & 4.23 \\
1826 & 1.52 & 1.53 & 2.79 & 2.67 & 4.31 & 4.20 \\
1831 & 1.53 & 1.55 & 2.77 & 2.65 & 4.30 & 4.21 \\
1836 & 1.59 & 1.59 & 2.70 & 2.71 & 4.29 & 4.30 \\
1841 & 1.54 & 1.59 & 2.76 & 2.70 & 4.30 & 4.29 \\
1846 & 1.57 & 1.54 & 2.68 & 2.75 & 4.25 & 4.29 \\
1851 & 1.62 & 1.56 & 2.59 & 2.65 & 4.21 & 4.21 \\
1856 & 1.59 & 1.54 & 2.48 & 2.57 & 4.07 & 4.10 \\
1861 & 1.57 & 1.56 & 2.35 & 2.43 & 3.92 & 4.00 \\
1866 & 1.56 & 1.50 & 2.20 & 2.19 & 3.76 & 3.69 \\
1871 & 1.57 & 1.52 & 2.06 & 1.91 & 3.63 & 3.43 \\
1876 & 1.60 & 1.48 & 1.88 & 1.76 & 3.48 & 3.25 \\
1881 & 1.60 & 1.49 & 1.59 & 1.55 & 3.19 & 3.04 \\
1886 & 1.51 & 1.44 & 1.35 & 1.39 & 2.86 & 2.84 \\
1891 & 1.40 & 1.45 & 1.09 & 1.23 & 2.49 & 2.68 \\
1896 & 1.29 & 1.41 & 0.86 & 1.09 & 2.15 & 2.49 \\
1901 & 1.10 & 1.39 & 0.79 & 0.96 & 1.89 & 2.34 \\
1906 & 0.97 & 1.35 & 0.86 & 0.86 & 1.83 & 2.20 \\
1911 & 0.97 & 1.36 & 0.93 & 0.75 & 1.90 & 2.11 \\
1916 & 1.18 & 1.35 & 0.82 & 0.69 & 2.00 & 2.03 \\
1921 & 1.35 & 1.36 & 0.70 & 0.61 & 2.05 & 1.98 \\
1926 & 1.41 & 1.34 & 0.66 & 0.57 & 2.07 & 1.91 \\
1931 & 1.51 & 1.36 & 0.63 & 0.53 & 2.14 & 1.88 \\
1936 & 1.60 & 1.36 & 0.54 & 0.49 & 2.14 & 1.85 \\
1941 & 1.55 & 1.38 & 0.49 & 0.46 & 2.04 & 1.83 \\
1946 & 1.51 & 1.38 & 0.46 & 0.44 & 1.97 & 1.82 \\
Mean & 1.58 & 1.57 & 2.00 & 1.99 & 3.58 & 3.57 \\
Bias & & -0.003 & & -0.009 & & -0.012 \\
RMSE & 0.147 & & 0.147 & & 0.237 \\
\hline & & & & & & \\
\hline
\end{tabular}


increases this constraint becomes less important and, therefore, parents would reduce second-period fertility even if there were no interaction terms in utility (i.e., $\alpha_{21}=\alpha_{22}=0$ ). However, the estimates suggest that this effect alone is not sufficient to fit the data. ${ }^{11}$

The goods cost of a child birth is .1129 in both fertility periods. ${ }^{12}$ This amounts to 11 percent of the 1736 cohort's first-period full income. The time cost associated with rearing a child that survives to age 15 is estimated to be 29 percent of available time. The basic need parameter is less than one child for first-period fertility and less than two children for the total childbearing period. Hence, if fertility was at only the basic need level estimated by the model, population size would be declining.

Within-sample Fit:

The deviations in the predictions are small both in absolute value and relative to the means. The model, on average, understates first-period fertility by .003 children and understates second-period fertility by .009 children. Consequently, completed cohort fertility is understated by .012 children. The root mean square errors are also small, .147 for $n_{1 t}, .147$ for $n_{2 t}$, and .235 for $n_{t}$, all of which are less than ten percent of their respective mean levels of fertility.

The predicted and actual fertility levels are graphed in Figure 4. The bottom two curves correspond to the predicted and actual period one fertility levels, the middle two to the period two levels, and the top two to completed fertility levels. The Figure demonstrates that the seven parameter model fits the 86 data points (43 data points for each life cycle period) quite well. The only case in which the model deviates significantly from the actual data is for first-period fertility, and, hence, to a lesser degree for completed fertility, for the cohorts born between 1896 and 1916. The observed temporary decline

\footnotetext{
${ }^{11}$ When the further restriction that $\alpha_{21}=\alpha_{22}$ was imposed in estimation, consumption and surviving children were found to be substitutes in utility and the model predicted (incorrectly) that first period fertility would follow a downward trend for 20-th century cohorts.

${ }^{12}$ Allowing for different period-specific costs did not improve the fit of the model.
} 
in first-period fertility for women during the years 1911 to 1940 cannot be accounted for by the levels of mortality and real wages that were experienced over their life cycles. Other exogenous events, such as high recruitment into the army and the delay of marriages during World War I, are required to explain this decline.

\section{$5 \quad$ Explaining the Fertility Trends}

In order to understand the determinants of the demographic transition in Sweden, we looked at the consequences for completed cohort fertility of six counterfactual experiments based on the predictions of the model using the estimated parameter values. The results are shown in Figure 5 and Table 3. The counterfactual experiments are meant to isolate the relative importance of the wage increase and the survival rate changes on the patterns of the demographic transition. The experiments are as follows:

Experiment 1 - a world in which infant and child mortality rates follow their historical pattern, but real wages and adult mortality rates are fixed at their average 1750-1795 values.

Experiment 2 - a world in which real wages follow their historical pattern, but all age- specific mortality rates are set equal to their average 1750-1795 values.

Experiment 3 - a world in which adult mortality rates follow their historical pattern, but real wages and infant and child mortality rates are fixed at their average $1750-1795$ values.

Experiment 4 - a world in which infant and child mortality rates and real wages follow their historical pattern, but adult mortality rates are fixed at their average 1750-1795 values.

Experiment 5 - a world in which adult mortality rates and real wages follow their historical pattern, but infant and child mortality rates are fixed at their average $1750-1795$ values. 
Experiment $6-$ a world in which mortality rates at all ages follow their historical pattern, but real wages are fixed at their average 1750-1795 values.

As seen in Figure 5, the behavioral model predicts that if only infant and child mortality rates had changed (experiment 1), then completed cohort fertility would have declined throughout the 19th and 20th centuries at a relatively constant rate. Quantitatively, between the 1856 and 1946 cohorts, completed fertility would have declined from about 4 children per woman to about 3.3 children per woman, a decline of .62 children. This is in contrast to the fall of 2.10 children that actually occurred over this period. Hence, the decline in infant and child mortality per se caused about $30 \%$ of the total fertility transition. Moreover, given the substantial decline in infant and child mortality, the number of children surviving to adulthood, as measured by $N_{2 t}$, would have increased, according to this experiment, over the same period from 2.83 children to 3.17 children, rather than exhibiting the substantial decline that actually occurred from 2.93 children to 1.95 children.

As the second experiment (experiment 2), also depicted in Figure 5, shows, if only the real wage path had followed its historical pattern, completed cohort fertility would have increased by 0.43 births from its initial level through the mid-19th century cohorts. It would have then fallen by 0.85 children between the 1856 and the 1946 cohorts, more steeply at first and flattening out later. The net effect of this hump-shaped time profile would have been to reduce fertility. ${ }^{13}$ As with the first experiment, if this had been the only change there would have been a considerably less pronounced transition in terms of completed fertility. However, unlike the first experiment, the number of surviving children, $N_{2 t}$ would have fallen. Between the 1856 and 1946 cohorts, the number of children surviving to adulthood declined by 0.98 children. According to the predictions of the experiment, the decline would have been by .52 children.

\footnotetext{
${ }^{13}$ For several countries it has been documented that the fertility response to the real wage increase had an inverted U-shape. Recently, Dahan and Tsiddon (1996) report on the evidence and provided an explanation based on income ditribution. In this paper the inverted U-shape is an outcome due only to the parameters of the utility function.
} 
Figure 5 also reveals that if only adult mortality had followed its historical path (experiment 3), completed cohort fertility would have remained roughly constant over the transition period. Given the constancy of the infant and child mortality rates in the experiment, the number of surviving children would have risen slightly.

Experiments 1 to 3 show that changes in each of the three variables separately would not have reduced fertility below the level of three children per woman for the 1946 cohort. The reduction in infant and child mortality rates was the most important factor. The real wage had some negative impact on fertility by itself but the reduction in adult mortality had no impact by itself. It also follows from these experiments that a simple addition of the single effects of the historical changes in mortality rates or real wages would not be able to explain the behavior of completed fertility during the demographic transition. The interaction of these effects, as predicted by the model, produced a decline of 2.28 children which is 9 percent larger than actual decline.

The interactions that are responsible for the combined effect enter the model in several places, as can be seen in the first order conditions (5). The time cost of children increases multiplicatively in the wage and in the infant and child survival rate. Prior to the demographic transition period, while the infant and child survival rate was increasing, real wages were basically stagnant. The cost of a surviving child was therefore constant, while the number of surviving children for a given number of births was rising. Therefore, the time cost of a birth, the wage times the survival rate, was rising, leading to fewer births. As real wages in the second half of the 19th century rose, this increasing cost of fertility was magnified. Another interaction occurs between the adult survival rate and the real wage. Higher survival rates to older ages increase the importance of the future by increasing the effective discount factor $\beta_{a t}$ in (5). As wages rise, because $\alpha_{22}<0$, the marginal utility of surviving children falls and this effect is magnified by higher discount factors.

The importance of these two interactions is illustrated in the lower part of Table 3, which summarizes the results of another three counterfactual experi- 
Table 3: Summary of Counterfactual Experiments*

\begin{tabular}{|l|l|l|l|l|l|l|l|l|l|}
\hline & \multicolumn{3}{|c|}{$n_{1 t}$} & \multicolumn{3}{c|}{$n_{2 t}$} & \multicolumn{3}{c|}{$n_{t}$} \\
& $1755_{-}$ & 1856 & 1946 & $175_{-}$ & 1856 & 1946 & \multicolumn{1}{|l}{$175_{-}$} & 1856 & 1946 \\
\hline Exp.1 & 1.85 & 1.55 & 1.24 & 2.81 & 2.43 & 2.12 & 4.66 & 3.98 & 3.36 \\
Exp.2 & 1.86 & 1.84 & 2.12 & 2.80 & 3.25 & 2.11 & 4.66 & 5.09 & 4.24 \\
Exp.3 & 1.83 & 1.85 & 1.88 & 2.79 & 2.74 & 2.74 & 4.63 & 4.58 & 4.62 \\
Actual & $\mathbf{1 . 8 0}$ & $\mathbf{1 . 5 9}$ & $\mathbf{1 . 5 1}$ & $\mathbf{2 . 5 1}$ & $\mathbf{2 . 4 8}$ & $\mathbf{0 . 4 6}$ & $\mathbf{4 . 3 2}$ & $\mathbf{4 . 0 7}$ & $\mathbf{1 . 9 7}$ \\
Predicted & $\mathbf{1 . 8 8}$ & $\mathbf{1 . 5 4}$ & $\mathbf{1 . 3 8}$ & $\mathbf{2 . 8 3}$ & $\mathbf{2 . 5 7}$ & $\mathbf{0 . 4 4}$ & $\mathbf{4 . 7 0}$ & $\mathbf{4 . 1 0}$ & $\mathbf{1 . 8 2}$ \\
\hline Exp.4 & 1.88 & 1.54 & 1.28 & 2.82 & 2.77 & 1.22 & 4.70 & 4.31 & 2.50 \\
Exp.5 & 1.86 & 1.84 & 2.27 & 2.80 & 2.99 & 0.81 & 4.66 & 4.83 & 3.08 \\
Exp.6 & 1.85 & 1.58 & 1.31 & 2.82 & 2.43 & 2.17 & 4.61 & 4.00 & 3.48 \\
\hline
\end{tabular}

- Experiment 1 - infant and child mortality rates follow their historical pattern, but real wages and adult mortality rates are fixed at their average $1750-1795$ values.

- Experiment 2 - real wages follow their historical pattern, but all agespecific mortality rates are set equal to their average $1750-1795$ values.

- Experiment 3 - adult mortality rates follow their historical pattern, but real wages and infant and child mortality rates are fixed at their average 1750-1795 values.

- Experiment 4 - infant and child mortality rates and real wages follow their historical pattern, but adult mortality rates are fixed at their average $1750-1795$ values.

- Experiment 5 - adult mortality rates and real wages follow their historical pattern, but infant and child mortality rates are fixed at their average $1750-1795$ values.

- Experiment 6 - mortality rates at all ages follow their historical pattern, but real wages are fixed at their average 1750-1795 values.

* $175_{\text {_ }}$ is the average of cohorts 1736 through 1751. 
ments. In experiments 4 to 6 we consider the effect on fertility of the historical changes in infant and child mortality rates, real wages and adult mortality rates, two at a time. Experiment 4 considers the joint impact of the first two. The single effects of changes in infant and child mortality rates and real wages on fertility would have been to reduce it by 1.30 and 0.42 children per woman, respectively. The combined effect of these two factors was to reduce predicted fertility by 2.20 children per woman, from 4.70 for cohorts born around 1750 to 2.50 for the cohort born in 1946. Similarly, experiment 5 demonstrates that the combined effect of changes in real wages and adult mortality rates was larger than the sum of the relevant separate effects.

The conclusion from these experiments is that the single most important factor in the reduction in fertility was the fall in infant and child mortality. By itself, it accounted for one-half of the reduction in completed ferti lity in Sweden between the mid-18'th and the mid-20'th centuries. Surprisingly, the increase in the real wage accounted by itself only for 20 percent of the reduced fertility and the fall in adult mortality rate, by itself, for none of the reduction.

These experiments also provide an explanation for the delay in the fertility response to the fall in infant and child mortality that is a characteristic of the demographic transition in many countries. As Figure 5 shows, the falling infant and child mortality rate, by itself, would have produced a steadily declining level of fertility, i.e., no delay. The observed relative constancy in fertility over the pre-transition period was caused by countervailing wage effects. However, increasing wages eventually induced lower fertility. The rapid rise in the real wage that began in the mid-1800's, amplified by interactions with survival rates, precipitated the abrupt transition. It is unnecessary to appeal to lagged perceptions, or to slow-changing customs, as a means of explaining this feature of the transition.

The second aspect of the Swedish demographic transition noted in section 3 was the concentration of the fall in fertility in the second life cycle period. Figures 6 and 7 show the paths of $n_{1 t}$ and $n_{2 t}$ that would be predicted to arise in each of the experiments. In experiment 1, lower infant and child 
mortality by itself would have produced a steady decline in both first and second period fertilities. Likewise, increased adult survival rates alone would have had very small effects on both period fertilities as seen in experiment 3 . However, consider experiment 2. If only real wages had followed their historical path, the movements in first-period fertility would have mirrored those in real wages whereas second-period fertility would have followed the same humpshaped profile predicted for completed fertility. Between the 1856 and 1946 cohorts, $n_{1 t}$ would have increased by 0.28 while $n_{2 t}$ would have fallen by 1.14 births. These different patterns occur because the marginal utility of children is essentially independent of consumption (income) in the first period, but falls with consumption in all subsequent periods.

Another difference between the two life-cycle periods emerges when we cumulate the changes in fertility predicted by each of the first three experiments. For first-period fertility, the sum of the effects, taken one at a time, between the 175_'s and 1946 is -0.30 as opposed to the decline of 0.50 births predicted by the model. In contrast, the decline predicted by the model for $n_{2 t}$ is much larger than the sum of individual effects (2.39 vs. 1.43). ${ }^{14}$

Therefore, the experiments show that the model matches the large increase in the ratio of first to second-period fertility which is observed in the data because it produces different responses of fertility to wage increases in the two life-cycle periods. This difference is amplified by interactions with adult survival rates. The experiments also show that the decline of about two children per woman between the 1856 and 1946 cohorts is a result of both the wage growth and the increase in survival rates of children and adults that occurred. Both aspects are important in explaining the characteristics of the Swedish demographic transition.

\footnotetext{
${ }^{14}$ That is, the interaction between infant-and-child survival rates and wages applies to both period fertilities whereas the interaction between adult survival rates and wages is effective only in the second and subsequent periods.
} 


\section{Predicting the Transition}

Another way to assess the credibility of the model is to consider the degree to which the model is able to forecast the demographic transition in terms of completed cohort fertility and life cycle patterns based on parameter estimates from a sample prior to the transition. To perform this exercise, we fit the model to a subsample consisting of the 25 cohorts born between 1736 and 1856 . The 1856 cohort is the last to have completed fertility of more than four children. Thus, the subsample covers the period prior to the fertility transition.

Table 4 is like Table 2, but in this case all results were obtained when the model was fit to the pre-transition subsample. As the top panel shows, $\alpha_{1}$ is $55 \%$ larger than the estimate based on the full sample, $\alpha_{21}$ has a small negative rather than a small positive value and $\alpha_{22}$ is very close to the result for the full sample. The birth cost $(b)$ and the time cost of children $(m)$ also are very close to the values obtained for the entire sample. The main difference in the estimates is that the basic need parameters are more than $50 \%$ lower now than for the entire sample.

The quality of the fit within sample is very good. The biases in first- and second-period fertility predictions are negligible (see Table 4). Since we used a subsample, relative to Table 2 we get lower RMSE's for the first 23 cohorts, but the differences are marginal: 0.110 vs 0.117 for the first period, 0.151 vs. 0.169 for second- period fertility. The lower part of Table 4 compares the predictions of the model for first- and second-period fertility and for completed fertility to their actual levels for each five-year cohort from 1861 through 1946. Figure 8 provides the companion graphical presentation.

The mean forecast error (bias) is -.110 for first-period fertility and -.792 for second- period fertility. The completed fertility forecast bias is therefore -.902, the simple addition of the two life cycle period forecast biases. The root mean squared errors are also large, .306 for $n_{1 t}, .817$ for $n_{2 t}$, and .932 for completed fertility.

As seen in Figure 8, the model predicts a smooth decline in first-period fer- 
Table 4: Pre-Transition Subsample: Results

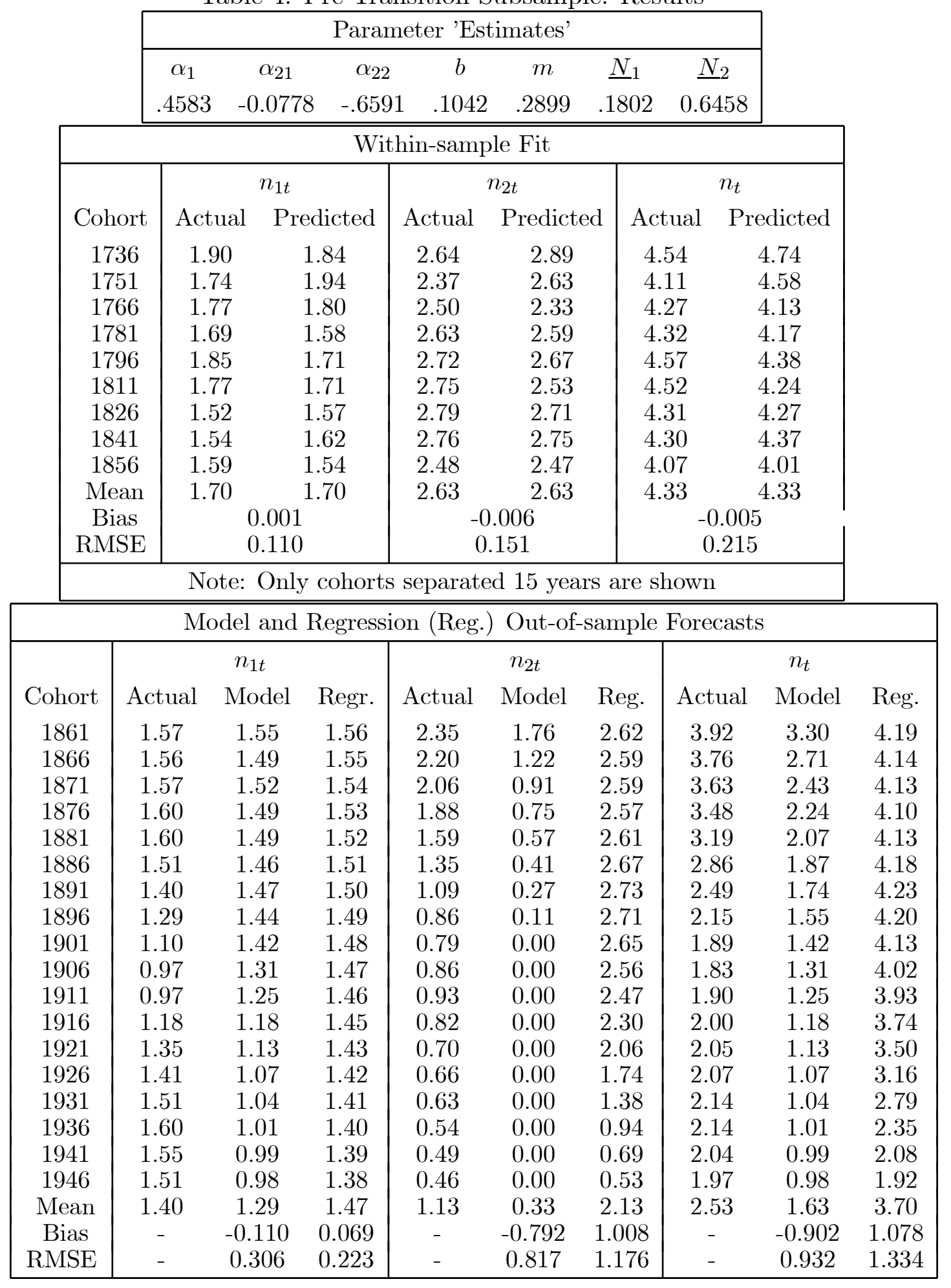


tility rather than the U-shaped pattern observed in the data for birth cohorts after 1856. With respect to second-period fertility the model predicts a rapid decline starting with the 1861 cohort, and for the 1901 and subsequent cohorts it predicts zero births. Thus, the decline in second-period fertility is also overstated. The model estimated using only pre- transition data overpredicts the decline in fertility that occurred during the demographic transition. ${ }^{15}$ To put it in a more dramatic way - economists using the model in 1900 (when information on completed fertility through the 1856 cohort was available) would have argued that economic incentives would cause fertility to drop substantially, dismissing completely the Malthusian hypothesis. ${ }^{16}$ In fact they would have argued that we should be concerned with the possibility of declining population in the developed economies. ${ }^{17}$

Regression Models:

It is more revealing to judge forecast accuracy against some reasonable benchmark. To provide such a benchmark, we estimated separate regressions over the 25 "pre-transition" observations of each period-specific fertility. We searched widely over specifications with the explicit intention of minimizing the root-mean square error of the out-of-sample forecast.

As may not be surprising given Figure 1, the best out-of-sample-fitting regression for $n_{1 t}$ is a simple linear trend. Adding variables from among the survival rates and real wages increases the root-mean square error of the forecast. The best fitting regression for $n_{2 t}$ is more complex. It contains a linear

\footnotetext{
${ }^{15}$ This result is most likely driven by the lower estimated values of the basic need parameters. Before 1900 fertility was far above basic need levels.

${ }^{16}$ Although 1856 is the last cohort with completed fertility greater than 4 (a clear landmark), ex post one can see that the permanent reduction in fertility started with the 1851 cohort. In order to examine the robustness of the above results we fitted the model to the data up to the 1851 cohort only. The parameters and the prediction results are very close to those reported in Table 4. In fact, second period fertility does not reach zero but the model still overpredicts the demographic transition.

${ }^{17}$ In this interpretation, we have implicitly assumed perfect foresight regarding future wages and survival rates, the same assumption as in the model's implementation.
} 
cohort trend, the level of real wages and infant mortality faced by the cohort in their second fertile period, the cohort's survival rate to age 60 conditional on survival to age 15 , and their fertility during their first fertile period, $n_{1 t}$, as would be consistent with a life cycle model

As seen in Table 4, the bias and mean square error of the regression forecasts are somewhat smaller than the model's for first-period fertility, but larger for second-period fertility. The regression predicts that the large decline in secondperiod fertility would occur much later than it actually did; this results in forecasts with a large positive bias. The sum of the forecasts obtained from each of these regressions provided a better forecast of completed fertility than did regressions on completed fertility itself. However, the bias and root-mean square error were still larger than those of the model's forecasts. The evidence is that, overall, the model performs no worse than the regressions in terms of out-of-sample forecasts.

\section{Concluding Remarks}

In this paper we investigated the causes of the fertility transition in Sweden using data on age-specific fertility, age-specific survival rates and aggregate wages between 1736 and 1946. The fertility transition in Sweden was characterized by a decline in total fertility from about four children per woman for the cohort born in 1856 to two children per woman for the cohort born in 1946. Almost all of this decline occurred for women at ages 30 through 45 , while fertility at younger ages stayed almost the same for more than two centuries. We analyzed this data using an OLG life cycle model of fertility choice. We fit a seven parameter specification of the model to data for all 43 birth cohorts. The model fit the data well, so we used the fitted model to quantify the relative importance of wage growth vs. survival rate increases in explaining the fertility transition. We found that wage increases and reductions in child mortality could account for a large part of the fertility decline 
in Sweden. However, their effect was magnified by interactions between the two, as well as by important interactions between an increasing real wage and rising adult survival rates.

We also asked whether an economist using this model around 1900 could have predicted the demographic transition. We fit the model to the data up to the 1856 cohort (i.e., the pre-transition data) and we computed its outof-sample forecasts. We found that the model overpredicts the transition, forecasting that women would have no children between the ages of 30 and 45 and that completed fertility would be lower than two children per woman. This result stands in stark contrast with the Malthusian view of fertility trends that most economists accepted at the turn of the century. Moreover, we were unable to improve on these forecasts when we ran time series regressions on the same data, searching over specifications with the explicit intention of minimizing the root-mean square error of the out-of-sample forecasts. 


\section{References}

[1] Becker, G. and Barro, R. 1988 "A Reformulation of the Economic Theory of Fertility". Quarterly Journal of Economics 103, 1-25.

[2] Becker, G., Murphy, K. and Tamura, R. 1990 "Human Capital, Fertility and Economic Growth". Journal of Political Economy 98, S12-S37.

[3] Coale, A. 1987 "Demographic Transition". in Eatwell, J.; Milgate, M.; and Newman, P. (eds.): The New Palgrave: A Dictionary of Economics.London: Macmillan.

[4] Dahan, M and Tsiddon, D. 1996 "Demographic Transition, Income Distribution, and Economic Growth". The Sackler Institute for Econopmic Research, Tel Aviv University, Working paper No. 42-96

[5] Eckstein, Z; Schultz, T.P.; and Wolpin, K. 1984 "Short-run Fluctuations in Fertility and Mortality in Pre-industrial Sweden". European Economic Review 26, 295-317.

[6] Eckstein, Z.; Stern, S.; and Wolpin, K. 1988 "Fertility Choice, Land and the Malthusian Hypothesis". International Economic Review 29, 352-361.

[7] Ehrlich, E. and Lui, F. 1991 "Intergenarational Trade, Longevity, and Economic Growth". Journal of Political Economy 99, 1029-1059.

[8] Fogel, R. 1994 "Economic Growth, Population Theory and Physiology: The Bearing of Long-Term Processes on the Making of Economic Policy". American Economic Review 84, 369-395.

[9] Galor, O. and Weil, D. 1996 "The Gender Gap, Fertility and Growth". American Economic Review 86, 374-387. 
[10] International Labour Office (various years) "Year-book of Labour Statistics". Geneva.

[11] Jorberg, L. 1972 "A history of prices in Sweden, 1732-1914". Lund, Gleerup.

[12] Lee, R. and Lapkoff, S. 1988 "Intergenerational Flows of Time and Goods: Consequences of Slowing Population Growth". Journal-ofPolitical-Economy 96, 618-51.

[13] Matthieson, P. and McCann, J. 1976 "The Role of Mortality in the European Fertility Transition". in S.H. Preston (ed.) The Effects of Infant and Child Mortality on Fertility. New York: Academic Press.

[14] Mitchell, B. 1975 "European Historical Statistics" New York: Columbia University Press.

[15] Razin, A. and Ben-Zion, U. 1975 "An Intergenerational Model of Population Growth". American Economic Review 69, 923-933.

[16] Statistika Centralbyran 1969 "Historical Statistics of Sweden Part 1: Population". Stockholm: Allmanna.

[17] Statistika Centralbyran (various years) "Statistical Yearbook of Sweden". Stockholm. 
Figure 1: Children Ever Born by Female Birth Cohort

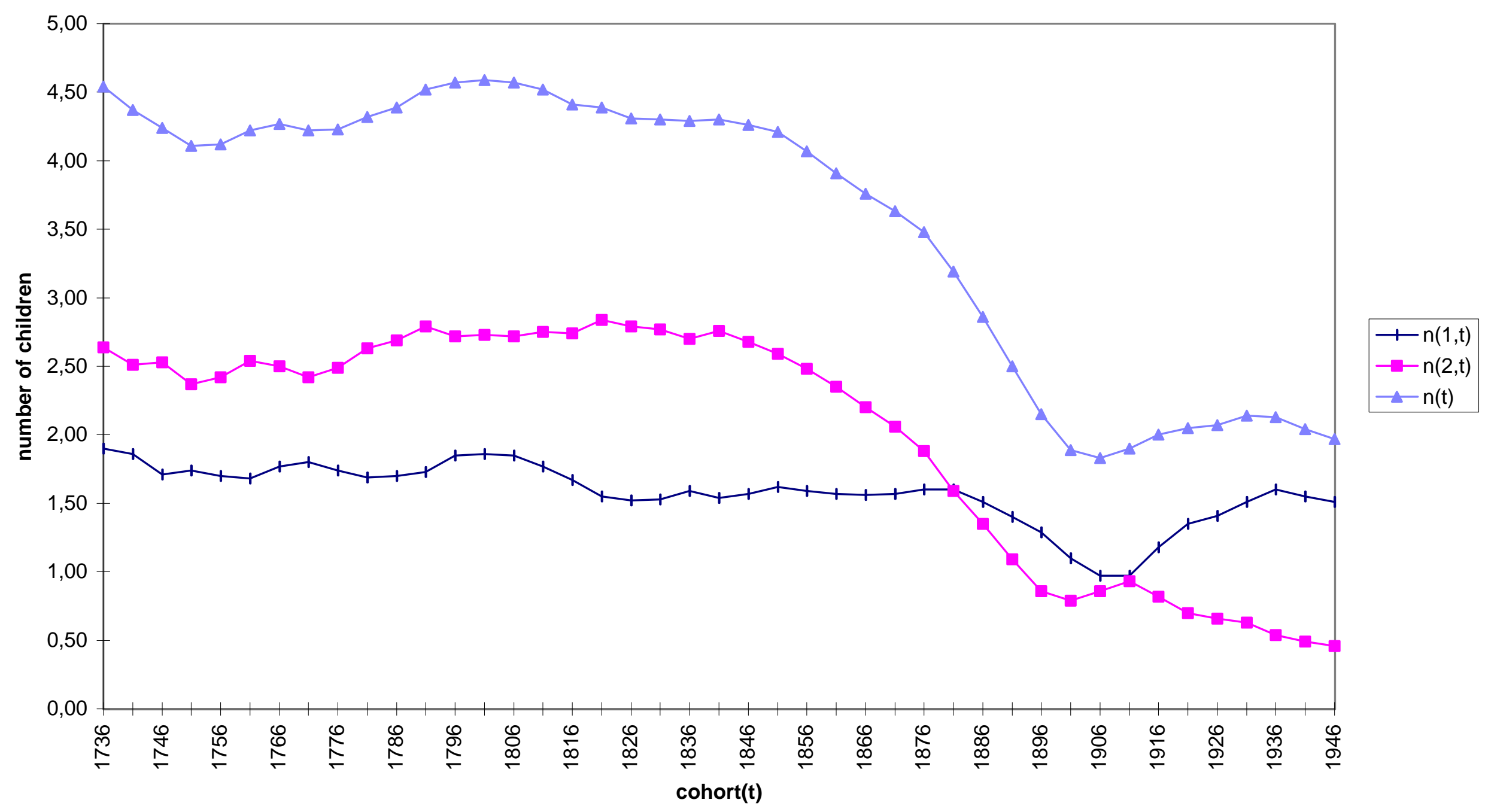


Figure 2: Survival Rates by Cohort

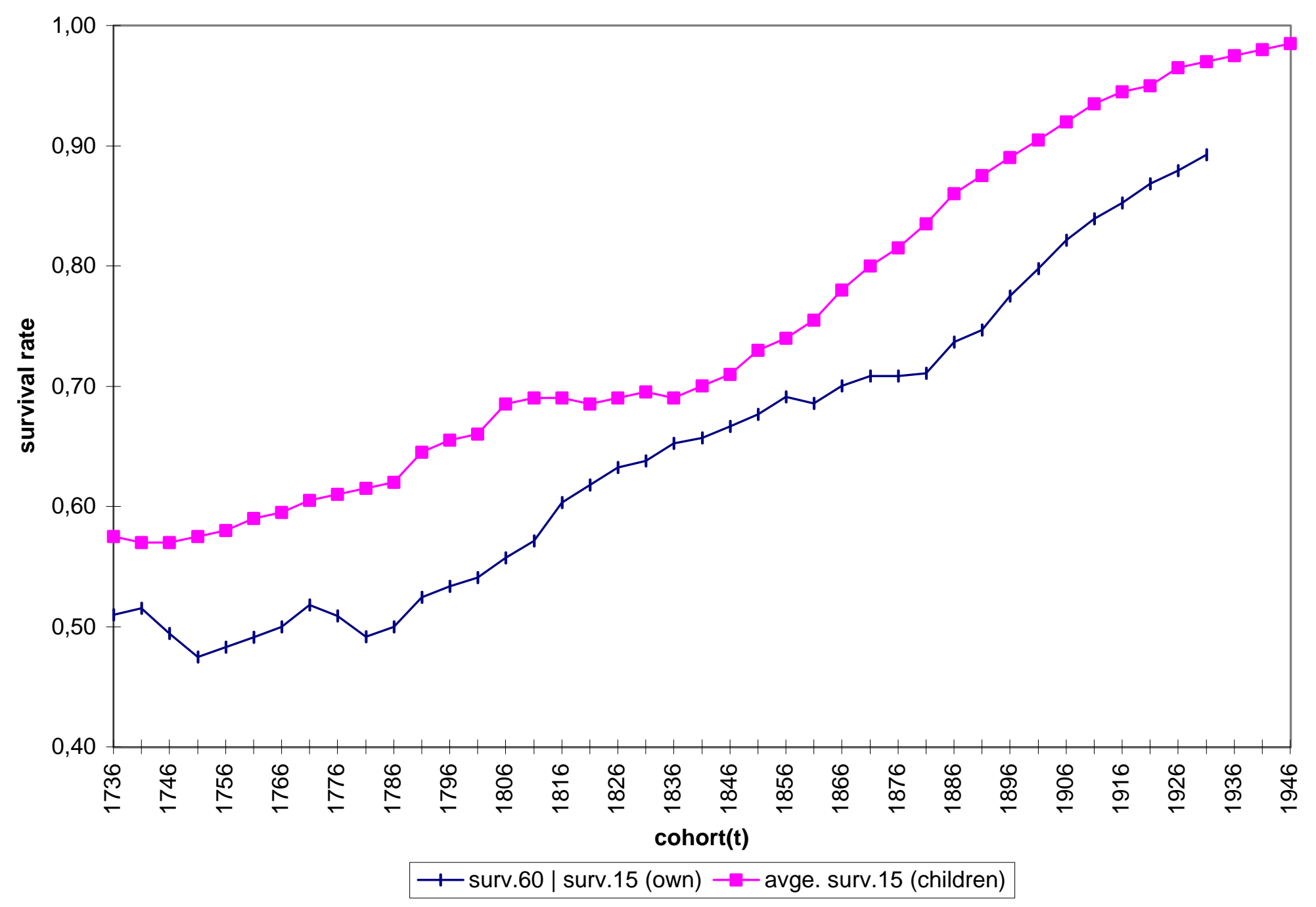


Figure 3: Ln Real Wage by Cohort and Period

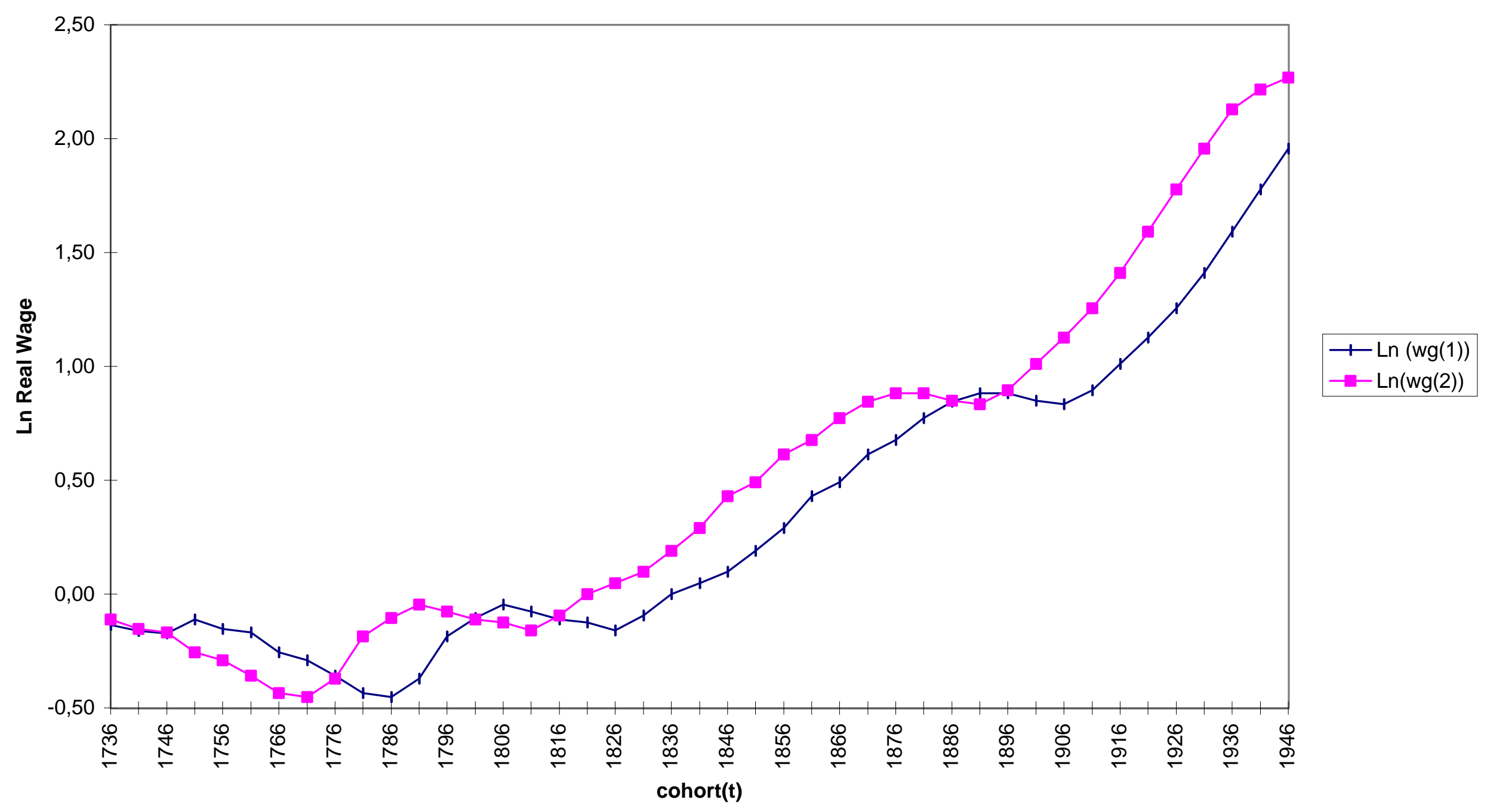


Figure 4: Actual and Predicted Fertility

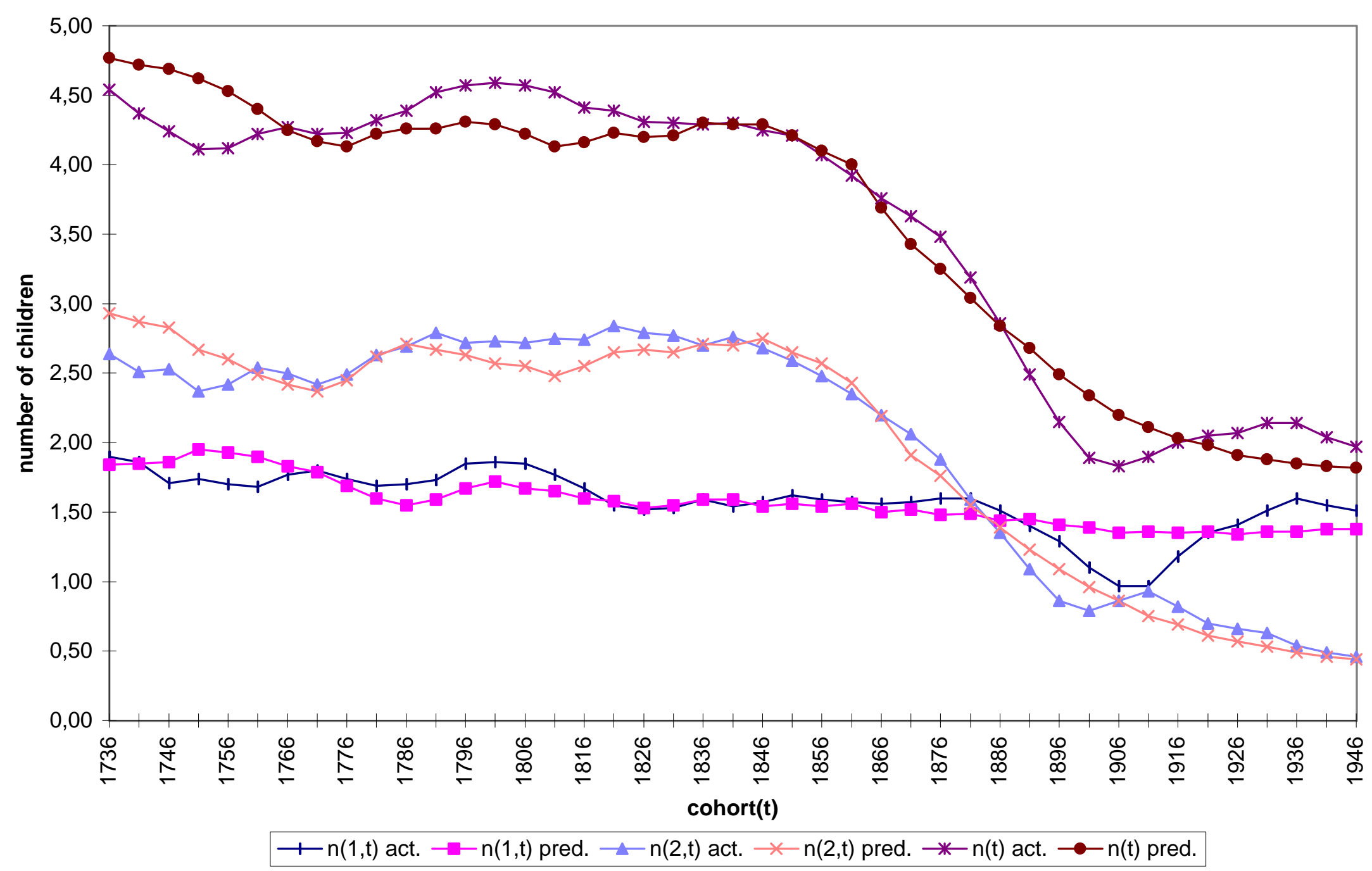


Figure 5: Counterfactual experiments - Total Fertility

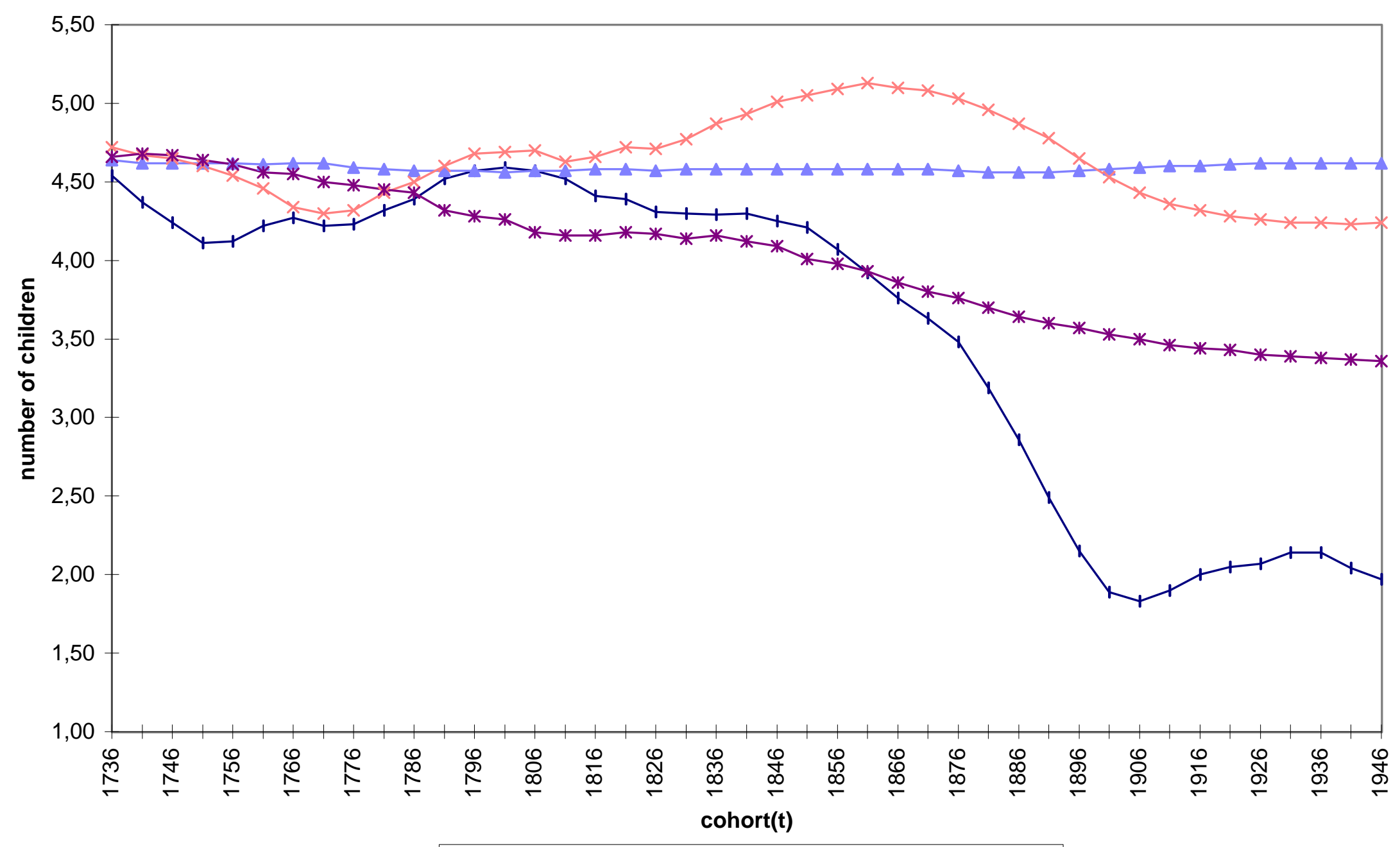

$\multimap \mathrm{n}(\mathrm{t})$ act. $\rightarrow \mathrm{n}(\mathrm{t}) \exp .3 \leftarrow \mathrm{n}(\mathrm{t}) \exp .2 \rightarrow \mathrm{n}(\mathrm{t}) \exp .1$ 
Figure 6: Counterfactual Experiments - First Period Fertility

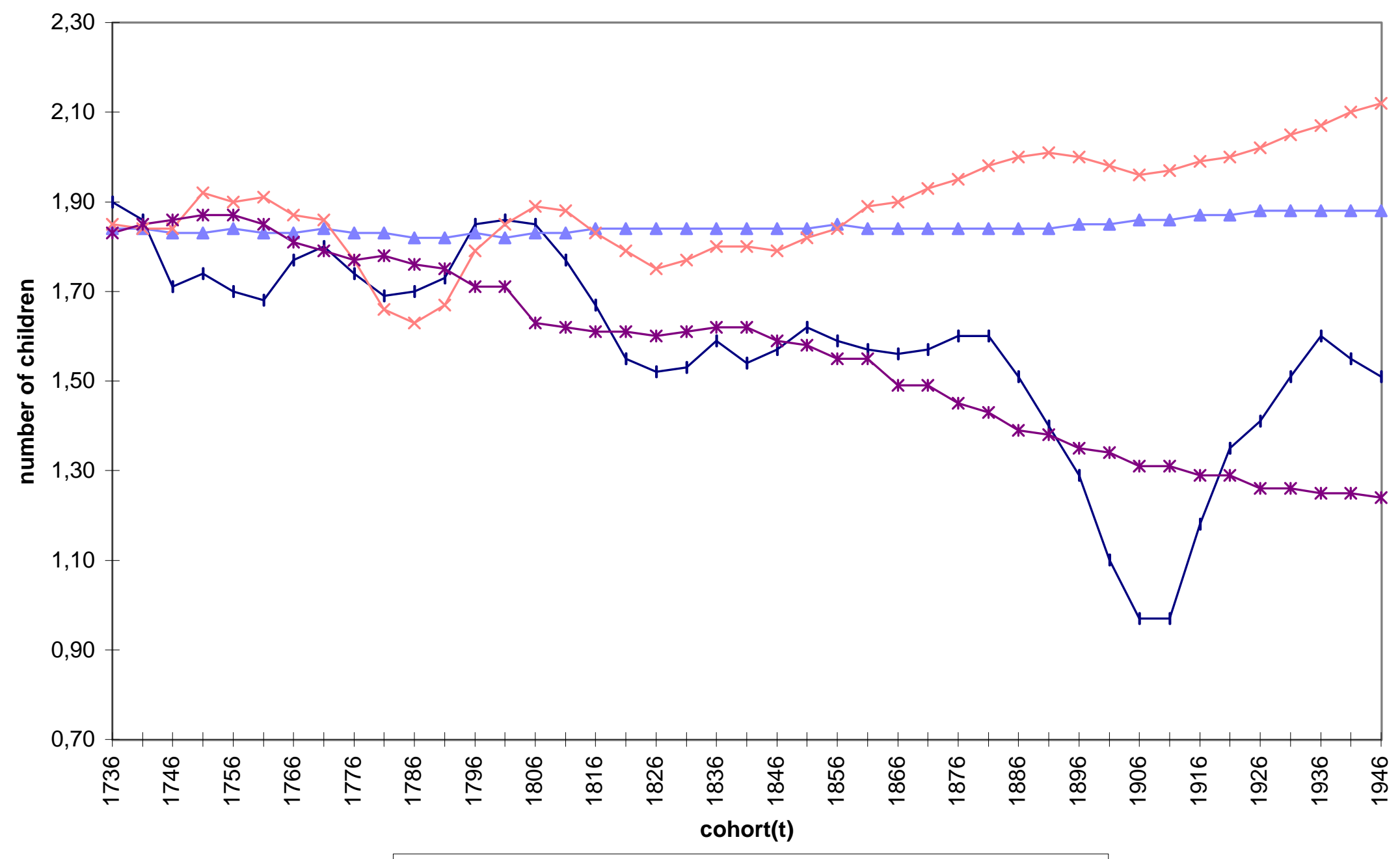

+ $\mathrm{n}(1, \mathrm{t})$ act. $\leftarrow \mathrm{n}(1, \mathrm{t})$ exp. $3 \leftarrow \mathrm{n}(1, \mathrm{t}) \exp .2 \rightarrow \mathrm{n}(1, \mathrm{t})$ exp. 1 
Figure 7: Counterfactual Experiments - Second Period Fertility

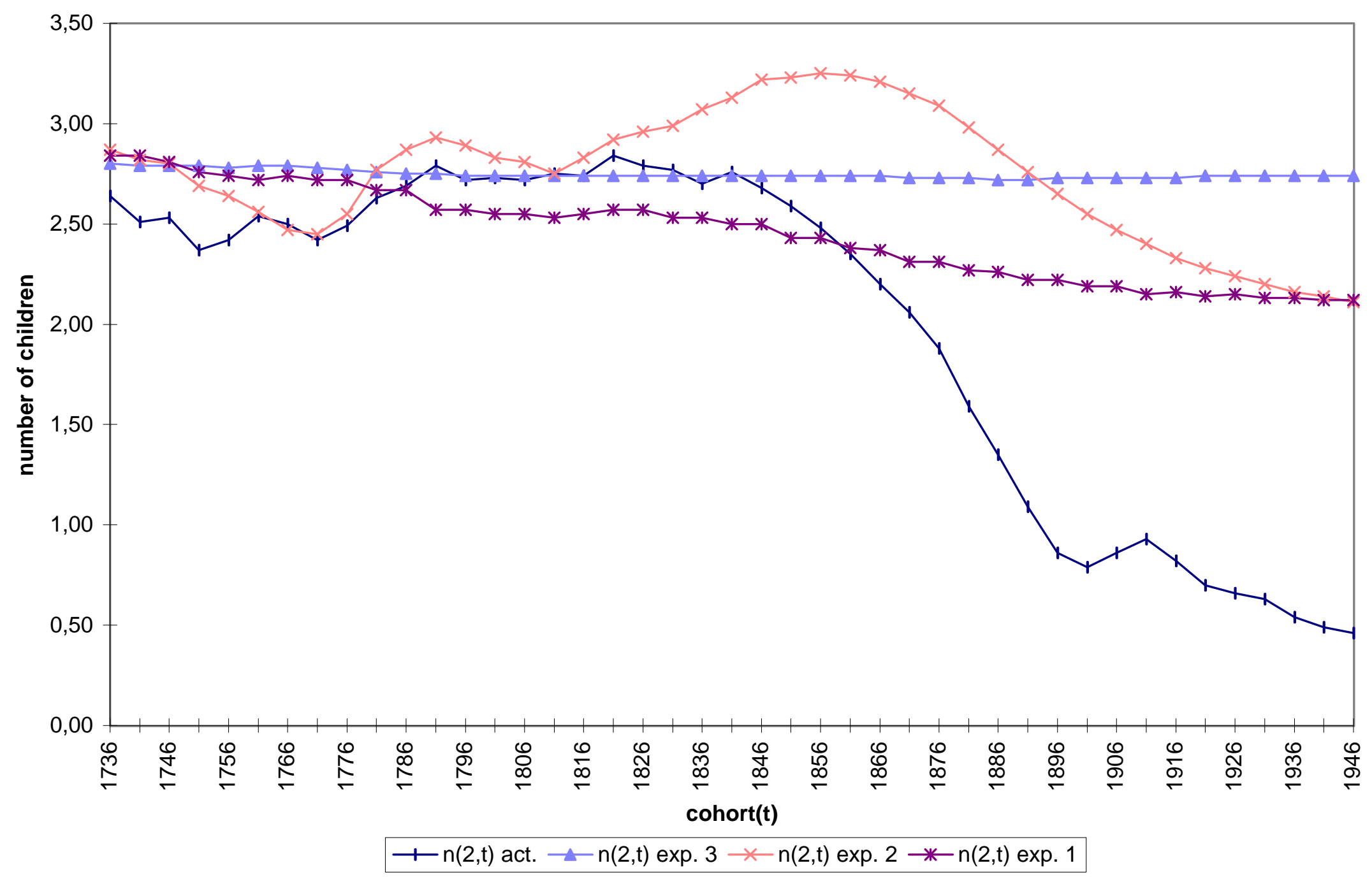


Figure 8a: Actual and Forecasted Fertility, Pre-transition Sample Estimates

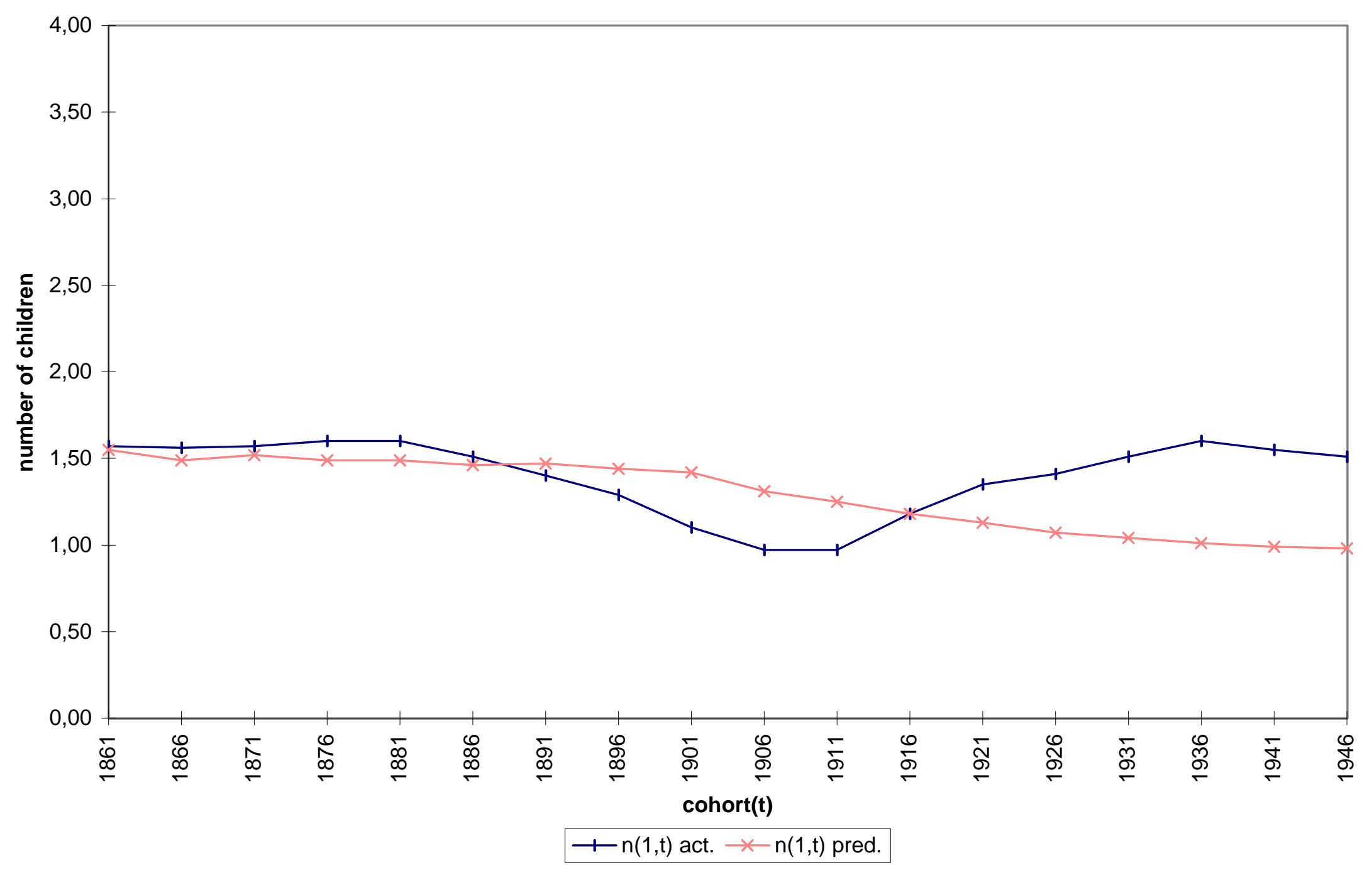


Figure 8b: Actual and Forecasted Fertility, Pre-transition Sample Estimates

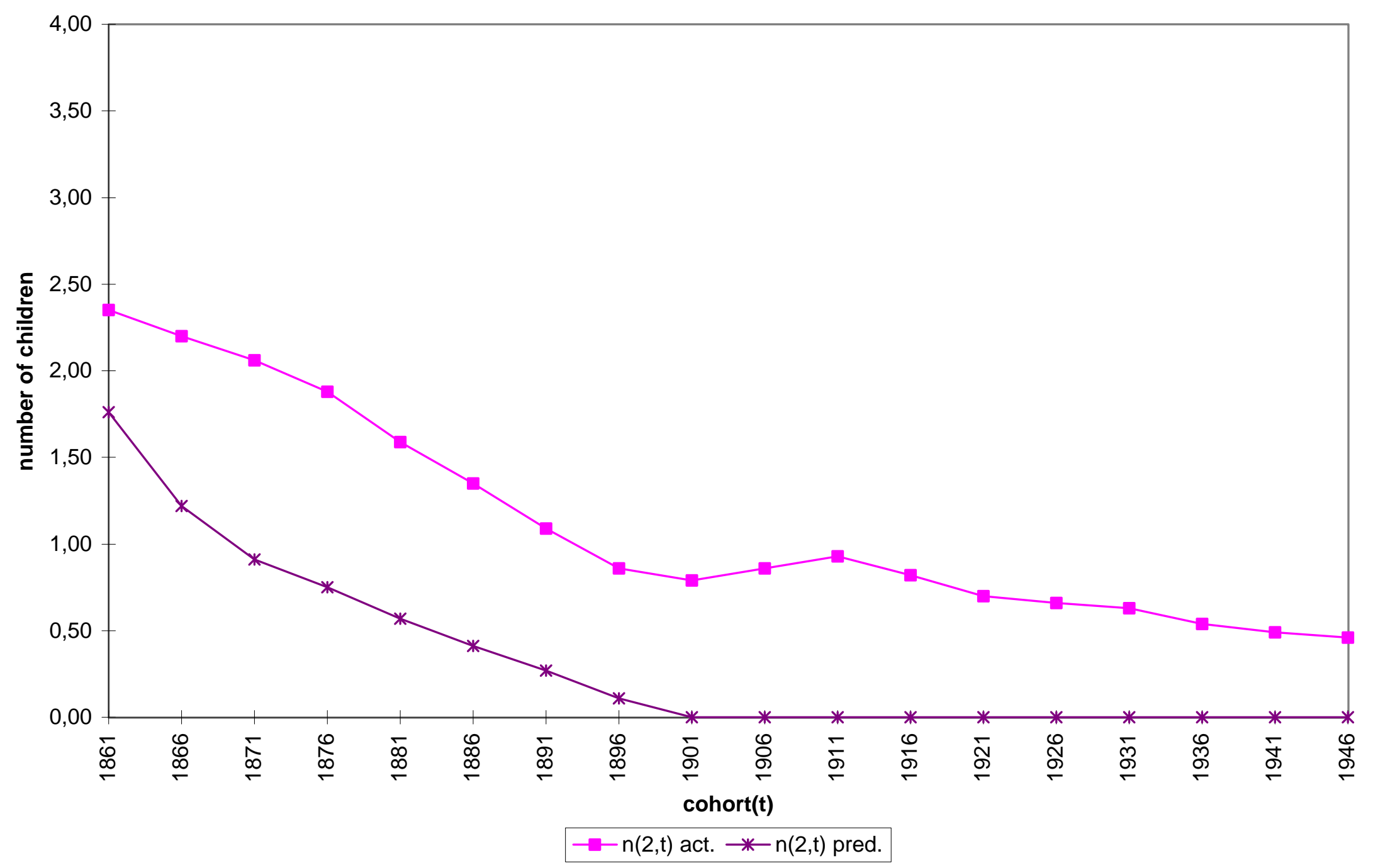


Figure 8c: Actual and Forecasted Fertility, Pre-transition Sample Estimates

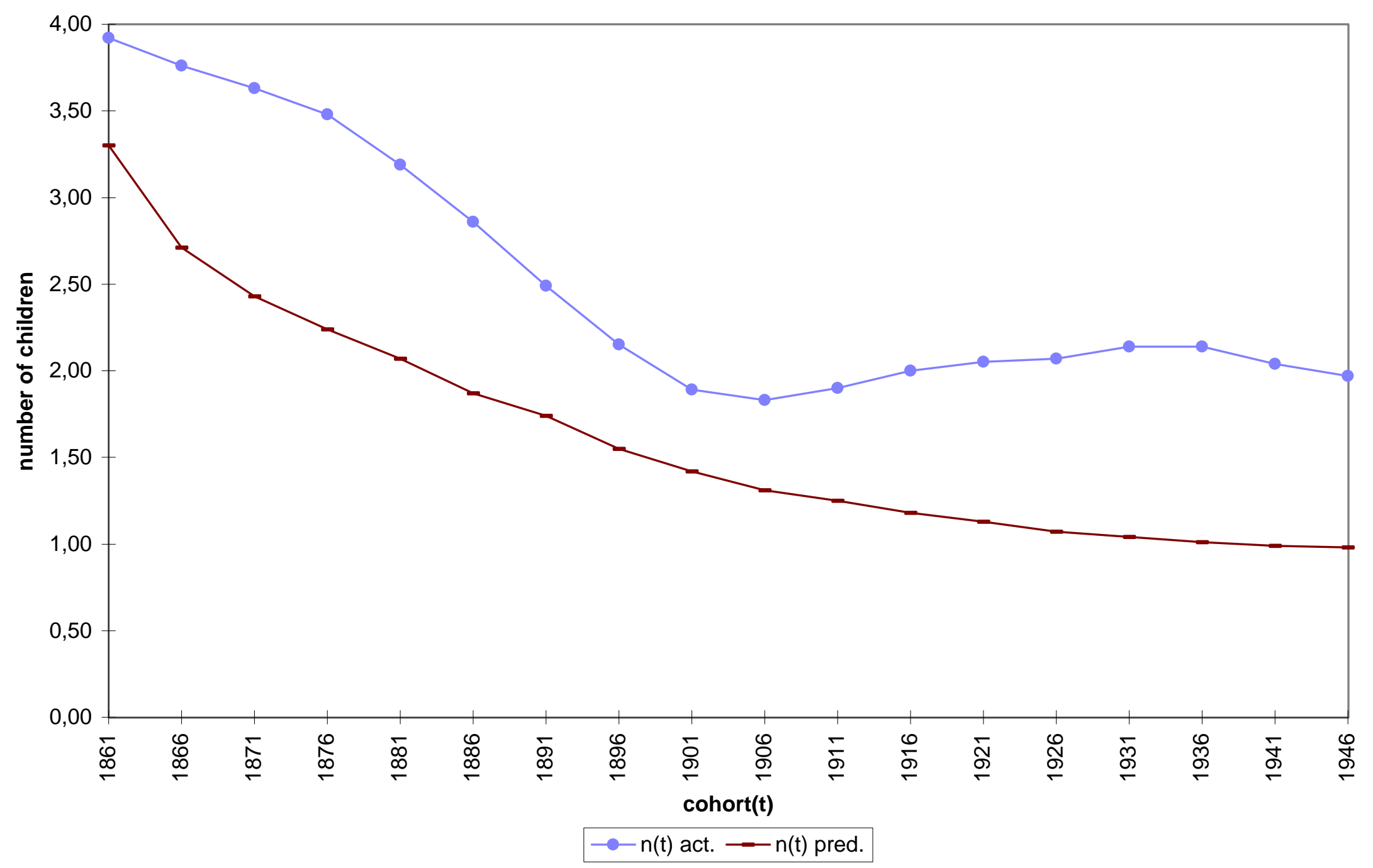

